\title{
Tapering of the Cervical Spinal Canal in Patients with Distended or Nondistended Syringes Secondary to Chiari Type I Malformation
}

\author{
Z. Zhu, S. Sha, X. Sun, Z. Liu, H. Yan, W. Zhu, Z. Wang, and Y. Qiu
}

\begin{abstract}
BACKGROUND AND PURPOSE: Steeper tapering of the cervical spinal canal as documented in recent studies is thought to have a role in the pathophysiology of Chiari malformation-associated syringomyelia. This study aimed to determine whether taper ratio of the cervical spinal canal differs between patients with distended and nondistended syringes.
\end{abstract}

MATERIALS AND METHODS: Seventy-seven adolescents (10-18 years) were divided into 2 groups: 44 with distended syrinx and 33 with nondistended syrinx. On T2-weighted MR images, anteroposterior diameter of the spinal canal was measured at each cervical level, and a linear trend line was fit by least squares regression to calculate the taper ratio. Taper ratios were compared between the 2 groups and further evaluated with respect to age and sex.

RESULTS: In the nondistended group ND, the taper ratios for Cl-C7, Cl-C4, and C4-C7 averaged $-0.73 \pm 0.57,-1.61 \pm 0.98$, and $-0.04 \pm 0.54$, respectively, all of which were significantly steeper than those observed in the distended group $(P=.001, .004$, and .033, respectively). Regarding the average diameters plotted by cervical level, the narrowest region of the canal was found to occur at C4 in both groups. In addition, no significant differences in taper ratio were noted between males and females, or between older ( $>14$ years) and younger patients ( $\leq 14$ years).

CONCLUSIONS: Taper ratios of the cervical spinal canal were found to be different between patients with distended and nondistended syringes, indicating a reciprocal interaction between the syrinx and the cervical spine anatomy.

ABBREVIATIONS: $\mathrm{CMI}=$ Chiari malformation type $\mathrm{I} ; \mathrm{SM}=$ syringomyelia; $\mathrm{D}=$ distended; $\mathrm{ND}=$ nondistended; $\mathrm{S} / \mathrm{C}=$ syrinx/cord

C hiari malformation type I (CMI) is the leading cause of syringomyelia (SM), a debilitating disorder that can give rise to neurologic impairments including motor weakness and sensory disturbance. ${ }^{1-3}$ To date, the exact pathogenesis responsible for SM associated with CMI remains incompletely understood. Although numerous theories and hypotheses have been proposed to explicate the mechanisms underlying such pathologic entity, ${ }^{4-7}$ none thoroughly elucidated the clinical and radiologic findings within the disease spectrum.

According to a prevailing concept, altered CSF flow at the craniovertebral junction is one of the essential elements in the

Received January 14, 2014; accepted after revision March 11.

From the Department of Spine Surgery, Drum Tower Hospital of Nanjing University Medical School, Nanjing, China.

S. Sha and Z. Zhu contributed equally to this work.

This work was supported by the National Natural Science Foundation of China (Grant No. 81171672).

Please address correspondence to Yong Qiu, MD, Department of Spine Surgery, Drum Tower Hospital of Nanjing University Medical School, Zhongshan Rd No. 321, Nanjing 210008, China; e-mail: scoliosis2002@sina.com

- Indicates open access to non-subscribers at www.ajnr.org

http://dx.doi.org/10.3174/ajnr.A3967 pathophysiology of SM and hypothetically causes the neurologic signs and symptoms associated with $\mathrm{CMI}^{8-11}$ Pinna et $\mathrm{al}^{12}$ reported that the elongation of the systolic flow might prolong the condition of elevated spinal subarachnoid pressure in patients with CMI. Using computational flow analysis in an idealized 3D model of the subarachnoid space, Roldan et $\mathrm{al}^{13}$ and Linge et $\mathrm{al}^{11}$ found that the peak CSF velocities increased progressively from the foramen magnum to C4 or C5. These findings, coupled with the mesodermal dysgenesis theory as evidenced by hypoplasia of the posterior cranial fossa, ${ }^{14,15}$ imply an abnormal cervical spinal canal anatomy in patients with CMI. In an attempt to verify this hypothesis, Hirano et $\mathrm{al}^{16}$ and Hammersley et $\mathrm{al}^{17}$ investigated tapering of the upper cervical spinal canal, and as steeper taper ratio was found in patients with CMI as compared with healthy controls, they speculated that such bony variations might increase the pressure gradients between the cranial and caudal ends of the spinal canal, resulting in dysfunctional CSF flow and thus favoring the formation of a syrinx.

Despite the elegance of the work of Hirano et $\mathrm{al}^{16}$ and Hammersley et al, ${ }^{17}$ which added an interesting twist to the pathomechanism of SM, their theory fails to account for the influence of a syrinx upon 
morphology of the cervical spinal canal. Clinically, it is observed that patients with a distended syrinx tend to have regional enlargement of the spinal canal. We, therefore, set out to determine whether taper ratio of the cervical spinal canal differs between patients with distended and nondistended syringes secondary to CMI.

\section{MATERIALS AND METHODS}

Our institutional review board approved this study and waived the requirement for written informed consent for the retrospective review of MR images and patient data.

\section{Subjects}

A 5-year retrospective review (between January 2008 and January 2013) was performed at our center on 170 consecutive patients with CMI-associated SM. The inclusion criteria were as follows: 1) age 10-18 years and 2) syrinx located within the cervicothoracic region. Patients with hydrocephalus, history of spinal trauma, changes of the sagittal cervical alignment (kyphosis or straightening), associated intraspinal anomalies, or congenital spinal deformity were excluded. A subset of 77 patients including 46 males and 31 females were ultimately enrolled for analyses.

All patients underwent MR scanning of the entire spinal cord with a $1.5 \mathrm{~T}$ MR imaging system (Gyroscan Intera; Philips Medical Systems, Best, the Netherlands). As a routine imaging protocol, sagittal images were obtained using T1-weighted (TR/TE, 717/10 ms; flip angle, $90^{\circ}$; field of view, $200 \mathrm{~mm}$; matrix, $168 \times 315$; NEX, 3 ) and T2-weighted (TR/TE, $2038 / 100 \mathrm{~ms}$; flip angle, $90^{\circ}$; field of view, $200 \mathrm{~mm}$; matrix, $168 \times 315$; NEX, 3) spin-echo techniques with $3-\mathrm{mm}$ sections and 2.5-mm intersection gaps. Based on the syrinx/cord (S/C) ratio defined as the maximal anteroposterior diameter of the syrinx divided by the anteroposterior diameter of the spinal cord at the same level on the transverse MR images (TR/TE, 2038/100 ms; flip angle, $90^{\circ}$; field of view, $300 \mathrm{~mm}$; matrix, $248 \times$ 306; NEX, 3), patients were subdivided into those with distended $(\mathrm{S} / \mathrm{C}>0.5)$ and nondistended $(\mathrm{S} / \mathrm{C} \leq 0.5)$ syringes. ${ }^{18,19}$

\section{Radiographic Measurements}

In line with the methods described previously, ${ }^{16,17}$ the anteroposterior diameter of the cervical spinal canal was measured on T2weighted MR images for each level at the midpoint of the vertebral body (in the case of $\mathrm{C} 1$, at the midportion of the anterior arch), along a line perpendicular to the spinal axis extending from the anterior to the posterior edge of the subarachnoid space (Fig 1). The diameters of the spinal canal were plotted against the cervical level. Then a linear trend line was fitted by least squares regression with an algorithm resident in the Excel spreadsheet (Microsoft, Redmond, Washington) (Fig 2), and the slope of this line was recorded as taper ratio $(\mathrm{mm} / \mathrm{level})$.

Location of the syrinx was recorded as the proximal and distal levels. The extent of tonsillar descent was evaluated on T1weighted MR images and classified into 3 grades $^{20}$ : grade I, where the tonsil extended below the foramen magnum but did not reach the $\mathrm{C} 1$ arch; grade II, where the tonsil reached the $\mathrm{C} 1 \mathrm{arch}$; and grade III, where the tonsil extended below the $\mathrm{C} 1 \mathrm{arch}$. Anteroposterior diameter of the foramen magnum as defined by the distance between the basion and the opisthion ${ }^{21}$ was also measured.

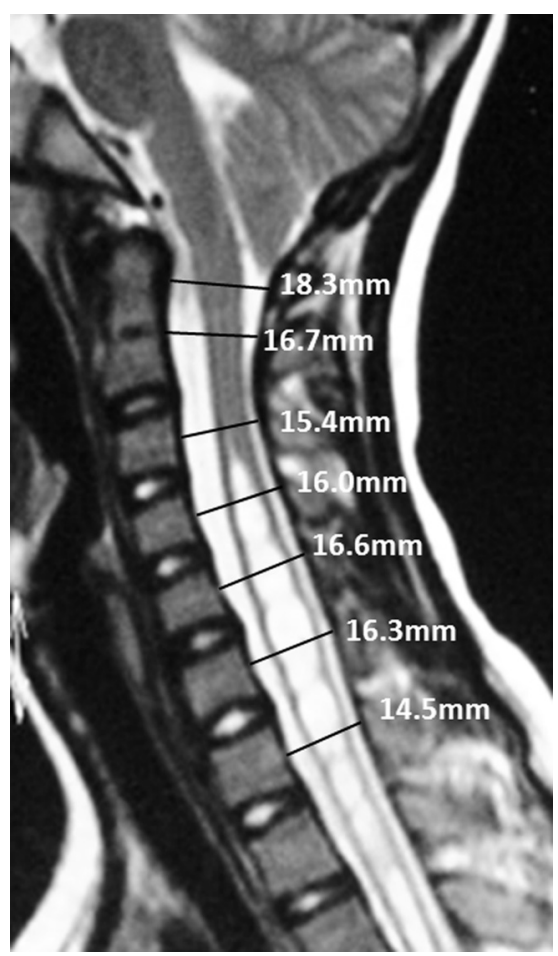

FIG 1. Sagittal T2-weighted MR image illustrating the measurement of the anteroposterior spinal canal diameter at 7 cervical levels.

\section{Statistical Analysis}

Data analysis was performed using SPSS 19.0 software (IBM, Armonk, New York). For comparisons of demographic data between the 2 groups, the Student $t$ test and $\chi^{2}$ analysis were applied for testing of continuous and categoric variables, respectively. The Fisher exact test was used for small data subsets $(n<5)$. The relationship between taper ratio and the anteroposterior diameter of the foramen magnum was assessed using the Spearman correlation test. Differences in taper ratios of the spinal canal (C1-C7, $\mathrm{C} 1-\mathrm{C} 4$, and $\mathrm{C} 4-\mathrm{C} 7)$ for the 2 groups were tested for significance by the Kruskal-Wallis test with significance set at .05.

\section{RESULTS}

Of the 77 patients, 44 were classified as having distended syrinx (group D), and 33 were assigned into the nondistended group (group ND). Table 1 summarizes the clinical and radiographic characteristics of patients in the 2 groups. The average age was $14.0 \pm 2.0$ years (range: $10-18$ years) for group D and $14.6 \pm 1.9$ years (range: $10-18$ years) for group ND. In group D, 25 patients were identified with grade I tonsillar ectopia, 16 with grade II, and 3 with grade III; in group ND, the corresponding values were 17 , 15 , and 1, respectively. Concerning the syrinx location, the proximal level varied from C2 to C5 in group D and from C2 to C6 in group ND, whereas the distal level for the 2 groups ranged, respectively, from C6 to T4 and from C6 to T3. None of the abovementioned parameters were found to be statistically different between the 2 groups $(P>.05)$.

Taper ratios for C1-C7 averaged $-0.34 \pm 0.54$ (range: $-2.03-$ $0.81)$ and $-0.73 \pm 0.57$ (range: $-1.88-0.98) \mathrm{mm} /$ levels, respectively, in groups $\mathrm{D}$ and ND $(P=.001)$. Regarding the other 2 
segments ( $\mathrm{C} 1-\mathrm{C} 4$ and $\mathrm{C} 4-\mathrm{C} 7)$, taper ratios were also noted to be significantly steeper in group ND than in group $\mathrm{D}(P=.004$ and .033, respectively; Fig 3).

Figure 4 illustrates the average anteroposterior diameters of spinal canal plotted by cervical level. In group D, spinal canal diameters averaged $17.2 \pm 2.5 \mathrm{~mm}$ (range: $12.7-22.5 \mathrm{~mm}$ ) at $\mathrm{C} 1$ and $15.3 \pm 2.1 \mathrm{~mm}$ (range: $11.9-20.5 \mathrm{~mm}$ ) at $\mathrm{C} 7$, whereas the average diameter at $\mathrm{C} 1$ and $\mathrm{C} 7$ in group ND was $19.0 \pm 3.4 \mathrm{~mm}$ (range: $11.2-24.7 \mathrm{~mm}$ ) and $14.5 \pm 2.5 \mathrm{~mm}$ (range: $11.2-22.8$

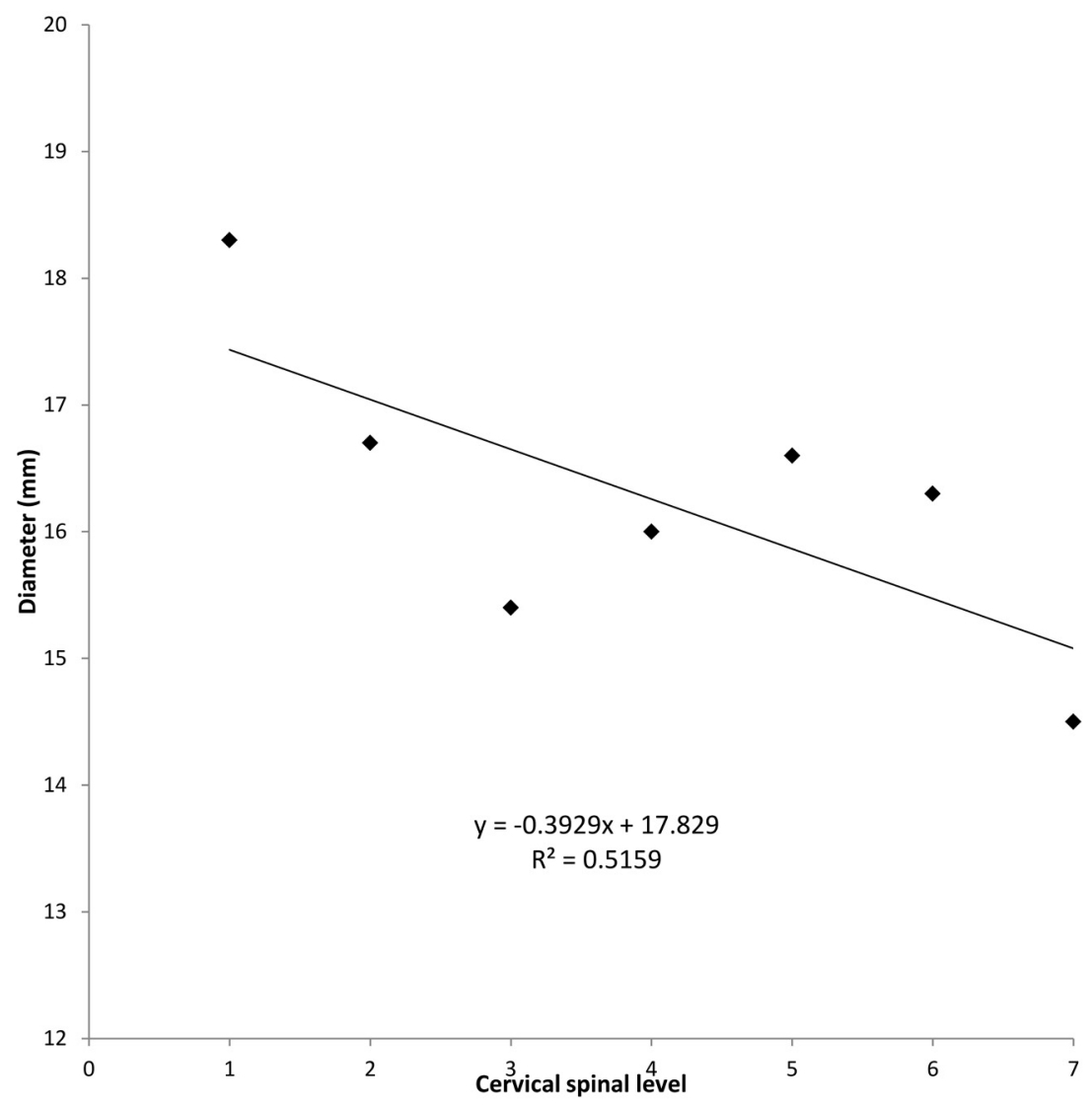

FIG 2. Plot of diameters of the cervical spinal canal for the patient in Fig 1 and the fitting of a trend line. The slope is $-0.39 \mathrm{~mm} /$ level, with the negative sign indicating the taper toward C7. $\mathrm{mm})$, respectively. In addition, the narrowest diameter was found to occur at the $\mathrm{C} 4$ level in both groups.

Taper ratios for $\mathrm{C} 1-\mathrm{C} 7$ were also analyzed with respect to age, sex, and the extent of tonsillar descent in each group (Table 2); however, no significant differences were noted between males and females, or between older ( $>14$ years) and younger patients ( $\leq 14$ years), or between patients with different grades (I, II, and III) of tonsillar ectopia $(P>.05)$. In addition, taper ratio of the cervical spinal canal was found to be marginally significantly correlated with the anteroposterior diameter of the foramen magnum (Spearman correlation, $-.221 ; P=.053)$

\section{DISCUSSION}

Syringomyelia has been reported to accompany CMI $20 \%-85 \%$ of the time and, if left untreated, may lead to progressive deterioration of the spinal cord function. ${ }^{22-24}$ Despite decades of research, the maintenance, propagation and, in particular, the pathogenesis of $\mathrm{SM}$ in association with CMI remain virtually obscure. As highlighted in the literature, dysfunctional CSF hydrodynamics arising from overcrowding of the caudal cranial fossa and downward displacement of the cerebellar tonsils may, in essence, be held responsible for the development of SM, with steeper pressure differentials across the foramen magnum or spinal levels precipitating accentuated pulsatile CSF subarachnoid waves during systole and diastole. ${ }^{8-11}$ No consensus, however, has hitherto been reached as to what primarily contributes to this pressure gradient.

Recently, the cervical spinal anatomy as a key component in the pathogenesis of CMI-associated SM has received in-

Table 1: Clinical and radiographic characteristics of patients in the 2 groups

\begin{tabular}{|c|c|c|c|}
\hline & Group D & Group ND & $P$ \\
\hline Number & 44 & 33 & \\
\hline Age (years) & $14.0 \pm 2.0(10-18)$ & $14.6 \pm 1.9(10-18)$ & NS \\
\hline Sex (male/female) & $26 / 18$ & $20 / 13$ & $N S^{a}$ \\
\hline Extent of tonsillar descent & & & $N S^{a}$ \\
\hline Grade I & 25 & 17 & \\
\hline Grade II & 16 & 15 & \\
\hline Grade III & 3 & 1 & \\
\hline Syrinx location & & & $N S^{b}$ \\
\hline Proximal level & $\mathrm{C} 2-\mathrm{C} 5$ & $\mathrm{C} 2-\mathrm{C} 6$ & \\
\hline Distal level & C6-T4 & $\mathrm{C} 6-\mathrm{T} 3$ & \\
\hline Syrinx/cord ratio & $0.70 \pm 0.10(0.51-0.88)$ & $0.39 \pm 0.09(0.19-0.50)$ & $<.001$ \\
\hline \multicolumn{4}{|l|}{ Taper ratio (mm/level) } \\
\hline $\mathrm{Cl}-\mathrm{C} 7$ & $-0.34 \pm 0.54(-2.03-0.81)$ & $-0.73 \pm 0.57(-1.88-0.98)$ & $.001^{\mathrm{c}}$ \\
\hline $\mathrm{Cl}-\mathrm{C} 4$ & $-0.98 \pm 0.87(-2.47-1.70)$ & $-1.61 \pm 0.98(-3.66-0.85)$ & $.004^{c}$ \\
\hline C4-C7 & $0.24 \pm 0.50(-0.85-1.65)$ & $-0.04 \pm 0.54(-0.97-1.36)$ & $.033^{\mathrm{c}}$ \\
\hline
\end{tabular}

Note:-NS indicates statistical nonsignificance.

${ }^{a} \chi^{2}$ test.

${ }^{\mathrm{b}}$ Fisher exact test.

' Kruskal-Wallis test or otherwise Student $t$ test. 

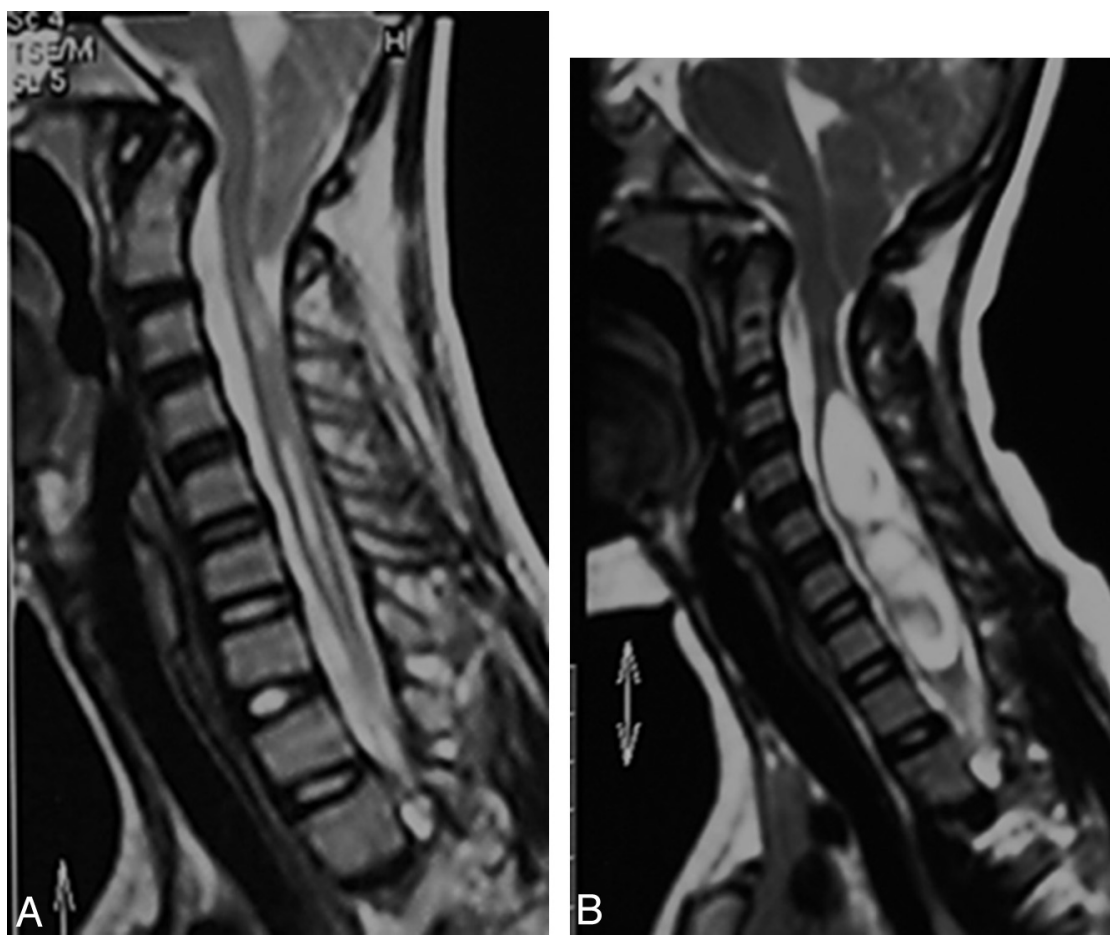

FIG 3. Two adolescents with Chiari malformation and syringomyelia. A, A 13-year-old male with nondistended syrinx. The taper ratios for $\mathrm{Cl}-\mathrm{C} 7, \mathrm{Cl}-\mathrm{C} 4$, and $\mathrm{C} 4-\mathrm{C} 7$ are $-1.52,-2.76$, and -0.22 , respectively. $B, A$ 12-year-old female with distended syrinx. The taper ratios for $\mathrm{Cl}-\mathrm{C} 7, \mathrm{Cl}-\mathrm{C} 4$, and C4-C7 are $0.79,0.63$, and 0.50 , respectively.

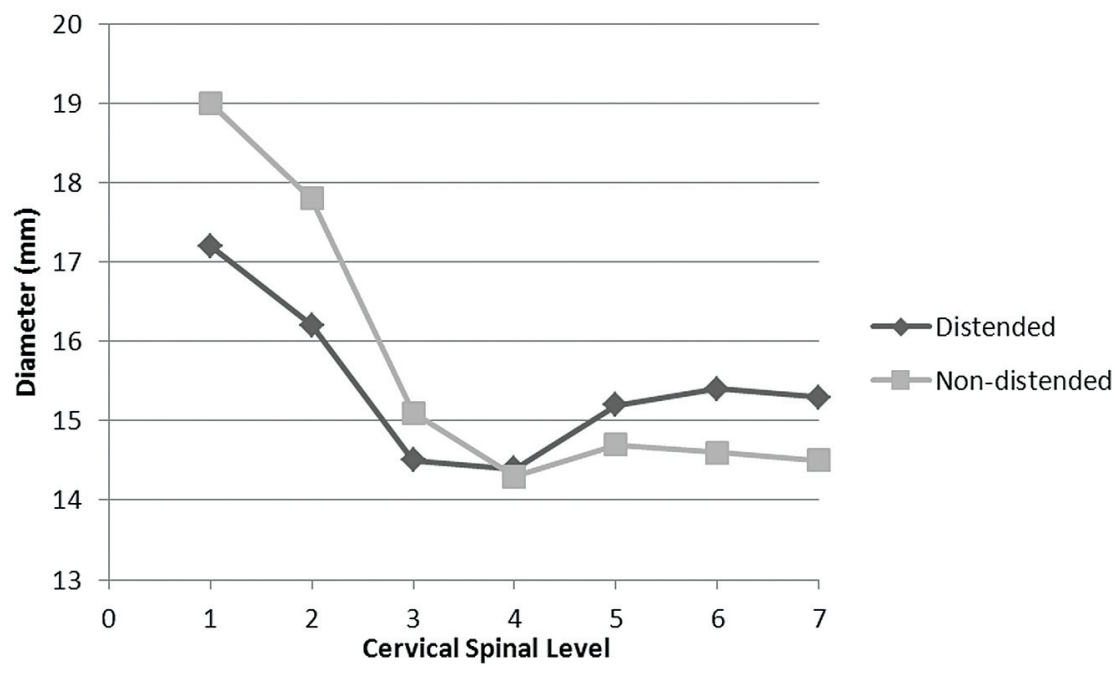

FIG 4. Average anteroposterior diameters of the cervical spinal canal plotted by cervical level in the 2 groups.

creasing concern. ${ }^{16,17}$ Hirano et al, ${ }^{16}$ in their retrospective review of 21 patients, noted a statistically steeper taper ratio of the upper cervical spinal canal in patients with CMI and SM. Concerning patients with CMI but no syrinx, however, taper ratio was found to be similar to that of their age- and sex-matched control subjects. These authors, therefore, surmised that steeper tapering of the spinal canal, in conjunction with obstruction of the subarachnoid space at the level of foramen magnum, could substantially increase the pressure gradient and subsequently accelerate the CSF velocities, leading to syrinx formation. Of note, their studies took an important first step in trying to elucidate the role of the cervical spinal canal anatomy in CMI, and brought to light an interesting and under-recognized phenomenon that may contribute to a better understanding of the pathophysiology of SM. Unfortunately, the small sample size, to some extent, restrained the validity of their findings. Bearing in mind the documented correlation between age and taper ratio, ${ }^{17}$ confounding bias might also be potentially induced by their relatively wide age range (from 4 to 60 years of age). To mitigate this bias and further clarify their findings, we analyzed the sagittal profiles of the cervical spinal canal on a larger but homogeneous cohort of adolescents with CMI. In addition, given that patients with a distended syrinx are more inclined to have a regional enlargement of the spinal canal than those with less extensive cavitation, we sought to determine whether disparities in the spinal geometry exist between the 2 subgroups.

In our series, the average taper ratios of the cervical spinal canal in patients with distended and nondistended syringes were both steeper than in the healthy controls reported previously $(-0.2 \pm 0.3 \mathrm{~mm} /$ level, on average $),{ }^{16}$ corroborating the conjecture of an abnormal development of the cervical spine in patients with CMI. Based on established hydrodynamics principles, the intrathoracic pressures are transmitted toward the spinal and cranial compartments and further to the subarachnoid space. ${ }^{25,26}$ Hence, one can hypothesize that in patients with CMI, the physiologic pressure transmission that normally exists between the intrathoracic and CSF compartments is exaggerated as a consequence of the steeper tapering of spinal canal, which, in turn, exacerbates the pressure differentials between the cranial and spinal compartments as well as their possibility of equalization, both of which are already altered by the herniated cerebellar tonsils. Intuitively, the elevated pressure differential may precipitate hyperkinetic CSF flow, and once a critical threshold is surpassed, a syrinx could be created. In addition, the anteroposterior diameter of the cervical spinal canal was found to be narrowest at $\mathrm{C} 4$ in both groups (Fig 4), corresponding with the results of prior studies that the peak CSF velocity increased progressively from the foramen magnum to $\mathrm{C} 4$ in patients with CMI. ${ }^{11,13,27}$ In light of these findings and the well-recognized association of syrinx with cervical canal stenosis, ${ }^{28,29}$ the pivotal role of cer- 
Table 2: Analyses of the taper ratio for $\mathrm{Cl}-\mathrm{C7}$ with respect to age and gender

\begin{tabular}{|c|c|c|c|c|}
\hline & \multicolumn{2}{|r|}{ Group D } & \multicolumn{2}{|r|}{ Group ND } \\
\hline & $N$ & Taper Ratio & $N$ & Taper Ratio \\
\hline \multicolumn{5}{|l|}{ Age } \\
\hline$\leq 14$ years & 28 & $-0.26 \pm 0.55$ & 12 & $-0.77 \pm 0.46$ \\
\hline$>14$ years & 16 & $-0.49 \pm 0.53$ & 21 & $-0.71 \pm 0.63$ \\
\hline$P$ & & .380 & & .750 \\
\hline \multicolumn{5}{|l|}{ Sex } \\
\hline Male & 26 & $-0.39 \pm 0.56$ & 20 & $-0.72 \pm 0.70$ \\
\hline Female & 18 & $-0.27 \pm 0.53$ & 13 & $-0.75 \pm 0.27$ \\
\hline$P$ & & .358 & & .883 \\
\hline \multicolumn{5}{|c|}{ Extent of tonsillar descent } \\
\hline Grade I & 25 & $-0.34 \pm 0.62$ & 17 & $-0.79 \pm 0.50$ \\
\hline Grade II & 16 & $-0.29 \pm 0.46$ & 15 & $-0.61 \pm 0.63$ \\
\hline Grade III & 3 & $-0.56 \pm 0.38$ & 1 & -1.37 \\
\hline$P$ & & .525 & & .335 \\
\hline
\end{tabular}

Note:-Statistical significance was tested using the Kruskal-Wallis test.

vical spinal canal dimensions in determining CSF circulatory features seems to be evident.

Theoretically, CSF circulatory disturbances may not only be associated with syrinx formation but also could influence the progression of SM, because its maintenance rests upon CSF being forced into the spinal cord by pulsatile pressure waves. ${ }^{6,30}$ Based on this assumption, the steeper the tapering is, the more abnormal the CSF dynamics and thus the larger the syrinx should be. Our results, however, demonstrated that patients with nondistended syrinx $(\mathrm{S} / \mathrm{C}$ ratio $\leq 0.5)$ had steeper taper ratios than those with distended syrinx $(\mathrm{S} / \mathrm{C}$ ratio $>0.5)$. In a previous study of 22 patients with CMI, Hammersley et $\mathrm{al}^{17}$ demonstrated that the taper ratio for $\mathrm{C} 1-\mathrm{C} 7$ was similar between patients with CMI plus syrinx and those with CMI only; however, the fact that only 2 patients were included in the latter group made this finding somewhat less convincing. Given that the local bone growth may be influenced by the size of the spinal cord in early development, as evidenced by the experimental work from Holtzer, ${ }^{31}$ a plausible explanation for our results is that the regional enlargement of the spinal cord caused by SM may exert an impact upon the development of the cervical spinal canal during skeletal maturation. Clarke et $\mathrm{al}^{9}$ reported that as a syrinx forms and enlarges, characteristics of the spinal subarachnoid space are altered, resulting in the CSF flow profile being stabilized or reverting to closer to normal, which indirectly supports our findings.

The correlation between age/sex and taper ratio has been documented in healthy adults and patients with CMI. ${ }^{16,32}$ Hirano et $\mathrm{al}^{16}$ reported that each increasing year of age was associated with a $0.03 \mathrm{~mm} /$ level decrease in the taper ratio in patients with CMI. In the present study, however, no significant difference in taper ratio was noted between older patients ( $>14$ years) and younger patients ( $\leq 14$ years) (Table 2 ), which presumably reflected the small sample sizes of the subgroups and also the narrow age range of subjects. We also looked into the possible relationship between sex and spinal canal diameters; however, no statistical correlation was found. Notably, a marginally significant correlation was demonstrated between taper ratio and the anteroposterior diameter of the foramen magnum $(r=-.221, P=.053)$, and this probably reflects the close anatomic relationship between the cervical spinal canal and the foremen magnum. In addition, no significant differences in taper ratio were found between patients with different grades of cerebellar tonsillar descent.

Importantly, the current study has for the first time unraveled the disparities in cervical spinal anatomy between patients with CMI with different syrinx morphologies, which, we anticipate, will shed further light on the integral role of cervical spinal canal dimensions in the pathophysiology of CMI-associated syringomyelia. Limitations of our study lie in its cross-sectional design and the lack of a control group. Consequently, future longitudinal studies involving both patients with CMI and healthy adolescents are warranted to expand our understanding of the reciprocal interactions between syringomyelia and the cervical spinal canal geometry. Subjects of this study were limited to adolescents to mitigate potential confounding bias. Tapering of the cervical spinal canal in the pediatric and adult population, therefore, still merits further investigation. In addition, the fact that more clinically severe syrinx cases are more likely to present for medical evaluation at an earlier time than those with less severe syrinx tends to induce a selection bias. Moreover, whether the relationship between syrinx size and spinal canal tapering observed in this study is an early developmental finding that remains relatively static or an evolving dynamic process has yet be explored by future studies.

\section{CONCLUSIONS}

Patients with nondistended syrinx have steeper tapering of the cervical spinal canal than those with distended syrinx, indicating a reciprocal interaction between the syrinx and the cervical spine anatomy. The integral role of spinal canal dimensions in the pathogenesis of syringomyelia, however, has yet to be explored by longitudinal studies involving both patients with CMI and healthy controls.

\section{REFERENCES}

1. Qiu Y, Zhu Z, Wang B, et al. Radiological presentations in relation to curve severity in scoliosis associated with syringomyelia. J Pediatr Orthop 2008;28:128-33

2. Sha S, Zhu Z, Sun X, et al. Effectiveness of brace treatment of Chiari malformation-associated scoliosis after posterior fossa decompression: a comparison with idiopathic scoliosis. Spine 2013;38:E299-305

3. Qiu Y, Zhu F, Wang B, et al. Clinical etiological classification of scoliosis: report of 1289 cases. Orthop Surg 2009;1:12-16

4. Gardner WJ. Hydrodynamic factors in Dandy-Walker and ArnoldChiari malformations. Childs Brain 1977;3:200-12

5. Williams $B$. The distending force in the production of communicating syringomyelia. Lancet 1970;2:41-42

6. Heiss JD, Patronas N, DeVroom HL, et al. Elucidating the pathophysiology of syringomyelia. J Neurosurg 1999;91:553-62

7. Josephson A, Greitz D, Klason T, et al. A spinal thecal sac constriction model supports the theory that induced pressure gradients in the cord cause edema and cyst formation. Neurosurgery 2001;48: 636-45

8. Clarke EC, Fletcher DF, Stoodley MA, et al. Computational fluid dynamics modelling of cerebrospinal fluid pressure in Chiari malformation and syringomyelia. J Biomech 2013;46:1801-09

9. Clarke EC, Stoodley MA, Bilston LE. Changes in temporal flow characteristics of CSF in Chiari malformation type I with and without syringomyelia: implications for theory of syrinx development. J Neurosurg 2013;118:1135-40

10. Hentschel S, Mardal KA, Lovgren AE, et al. Characterization of cyclic 
CSF flow in the foramen magnum and upper cervical spinal canal with MR flow imaging and computational fluid dynamics. AJNR Am J Neuroradiol 2010;31:997-1002

11. Linge SO, Haughton V, Lovgren AE, et al. CSF flow dynamics at the craniovertebral junction studied with an idealized model of the subarachnoid space and computational flow analysis. AJNR Am J Neuroradiol 2009;31:185-92

12. Pinna G, Alessandrini F, Alfieri A, et al. Cerebrospinal fluid flow dynamics study in Chiari I malformation: implications for syrinx formation. Neurosurg Focus 2000;8:E3

13. Roldan A, Wieben O, Haughton V, et al. Characterization of CSF hydrodynamics in the presence and absence of tonsillar ectopia by means of computational flow analysis. AJNR Am J Neuroradiol 2009;30:941-46

14. Stovner LJ, Bergan U, Nilsen G, et al. Posterior cranial fossa dimensions in the Chiari I malformation: relation to pathogenesis and clinical presentation. Neuroradiology 1993;35:113-18

15. Nishikawa M, Sakamoto H, Hakuba A, et al. Pathogenesis of Chiari malformation: a morphometric study of the posterior cranial fossa. J Neurosurg 1997;86:40-47

16. Hirano M, Haughton V, Munoz del Rio A. Tapering of the cervical spinal canal in patients with Chiari I malformations. AJNR Am J Neuroradiol 2012;33:1326-30

17. Hammersley J, Haughton V, Wang Y, et al. Tapering of the cervical spinal canal in patients with scoliosis with and without the Chiari I malformation. AJNR Am J Neuroradiol 2012;33:1752-55

18. Zhu Z, Qiu Y, Wang B, et al. Abnormal spreading and subunit expression of junctional acetylcholine receptors of paraspinal muscles in scoliosis associated with syringomyelia. Spine 2007;32: 2449-54

19. Qiu Y, Zhu Z, Wang B, et al. Abnormal spread of junctional acetylcholine receptor of paraspinal muscles in scoliosis associated with syringomyelia. Stud Health Technol Inform 2006;123:117-22

20. Ono A, Ueyama K, Okada A, et al. Adult scoliosis in syringomyelia associated with Chiari I malformation. Spine 2002;27:E23-28
21. Schady W, Metcalfe RA, Butler P. The incidence of craniocervical bony anomalies in the adult Chiari malformation. J Neurol Sci 1987;82:193-203

22. Dyste GN, Menezes AH, VanGilder JC. Symptomatic Chiari malformations. An analysis of presentation, management, and long-term outcome. J Neurosurg 1989;71:159-68

23. Tubbs RS, McGirt MJ, Oakes WJ. Surgical experience in 130 pediatric patients with Chiari I malformations. J Neurosurg 2003; 99:291-96

24. Park JK, Gleason PL, Madsen JR, et al. Presentation and management of Chiari I malformation in children. Pediatr Neurosurg 1997;26:190-96

25. Hamilton WF, Woodbury RA, Harper HT. Physiologic relationships between intrathoracic, intraspinal, and arterial pressures. JAMA 1936;107:853-56

26. Herlihy WF. Revision of the venous system; the role of the vertebral veins. Med J Aust 1947;1:661-72

27. Shah S, Haughton V, del Rio AM. CSF flow through the upper cervical spinal canal in Chiari I malformation. AJNR Am J Neuroradiol 2011;32:1149-53

28. Martin BA, Labuda R, Royston TJ, et al. Spinal subarachnoid space pressure measurements in an in vitro spinal stenosis model: implications on syringomyelia theories. J Biomech Eng 2010;132:111007

29. Kato N, Tanaka T, Nagashima H, et al. Syrinx disappearance following laminoplasty in cervical canal stenosis associated with Chiari malformation-case report. Neurol Med Chir (Tokyo) 2010;50: $172-74$

30. Oldfield EH, Muraszko K, Shawker TH, et al. Pathophysiology of syringomyelia associated with Chiari I malformation of the cerebellar tonsils. Implications for diagnosis and treatment. J Neurosurg 1994;80:3-15

31. Holtzer O. Experimental analysis of development of spinal column. J Exp Zool 1952;121:121-47

32. Tatarek NE. Variation in the human cervical neural canal. Spine J 2005;5:623-31 